\title{
UMA TEORIADA
}

PREPONDERÂNCIADO

PODEREXECUTIVO.

\section{O sistema de comissões no Legislativo brasileiro*}

\section{Carlos Pereira \\ Bernardo Mueller}

\section{Introdução}

A literatura produzida pela escola da escolha racional sobre o funcionamento do sistema de comissões no Congresso dos EUA baseia-se no modelo principal-agente, no qual um principal delega tarefas para um agente num ambiente de informação assimétrica, de modo que o bom funcionamento da relação depende da criação de uma estrutura de incentivos que alinhe os interesses de ambas as partes. ${ }^{1}$ Nesta literatura, as comissões são entendidas como agentes, porém o principal varia de acordo com as três grandes teorias. Pela teoria distributiva (Weingast e Marshall, 1988; Shepsle e Weingast, 1987), as comissões servem aos propósitos de seus próprios membros, que usam este sistema como forma de obter ganhos de troca. Pela teoria informacional (Gilligan e Krehbiel, 1987; Krehbiel, 1991), o principal é a Câmara ou o plenário como um todo. De acordo com esta teoria, o plenário concede certos poderes às comissões como incentivo para que se especializem, adquiram informação e passem esta informação para o plenário. Finalmente, a teoria partidária (Cox e McCubbins, 1993 e 1994) vê o partido majoritário como o principal. Segundo seus adep- tos, as regras legislativas concedem ao partido majoritário uma série de vantagens e poderes especiais que são usados para controlar as ações das comissões em prol do interesse dos membros do partido.

Estas teorias foram desenvolvidas para o Congresso dos EUA e quase toda a literatura é específica à sua estrutura e instituições. Neste artigo, buscamos usar as idéias centrais desta literatura para analisar o sistema de comissões permanentes da Câmara dos Deputados no Brasil. Exis-

\footnotetext{
Este artigo é uma versão revisada de trabalho apresentado ao GT Instituições Políticas no XXIII Encontro Anual da Anpocs, Caxambu, MG, 19-23 de outubro de 1999. Gostaríamos de agradecer aos membros do GT pelos comentários e sugestões, em especial a Fernando Limongi, que foi nosso debatedor. Uma versão prévia do trabalho foi também apresentada na $3^{\text {rd }}$ Annual Conference of The International Society for the New Institutional Economics, Washington, 16-18 de setembro de 1999. Agradecemos a Philip Keefer pelos comentários. Gostaríamos ainda de expressar nossa gratidão a Eduardo Leoni e Tatiana Ribeiral pela colaboração no processo de coleta e operacionalização dos dados, bem como pelas sugestões e críticas oferecidas ao texto. Somos muito gratos também a Argelina Figueiredo e Fernando Limongi, por nos terem concedido acesso e compartilhado dados sobre a produção e tramitação da legislação na Câmara dos Deputados, e a Lúcio Renno, pelos comentários.
} 
tem, ao mesmo tempo, diversas similaridades e diferenças entre os Congressos destes países. Ambos são bicamerais em um regime presidencial e estruturados de acordo com um complexo sistema de comissões permanentes. Estas semelhanças, dentre outras, indicam que as teorias referidas podem oferecer caminhos para explicar o funcionamento do Congresso brasileiro. Por outro lado, várias diferenças importantes entre os dois Congressos, que serão destacadas aqui, sugerem que nenhuma dessas teorias será por si só capaz de cumprir essa tarefa. Sendo assim, o propósito do artigo é contribuir para a criação de uma teoria específica que explique o sistema de comissões do Congresso brasileiro. Tal teoria buscará, quando apropriado, incorporar o instrumental e as idéias das teorias citadas acima, porém deverá ser capaz de explicar as especificidades do caso brasileiro. Em particular, deverá ter como um de seus pressupostos centrais o fato de o Executivo brasileiro deter significativo poder de influenciar o processo legislativo para assegurar resultados consistentes com suas preferências. Por essa razão a chamamos de teoria da preponderância executiva

$\mathrm{Na}$ próxima seção apresentamos, de forma resumida, os poderes legislativos do Executivo brasileiro, ressaltando a sua extrema supremacia. ${ }^{2}$ Baseados nisto, tomamos como premissa que a existência e o funcionamento do sistema de comissões estão subordinados às preferências do Executivo. Ou seja, se as comissões estão prestando algum papel no processo legislativo, este não pode ser contrário aos interesses do Executivo, pois o Executivo tem diversos meios de contornar as comissões, forçá-las a cooperar ou punir seus desvios. Surge portanto a pergunta: o que as comissões podem fazer pelo Executivo? Dado que observamos que as comissões cumprem uma extensa gama de tarefas, e dada a premissa acima, a conclusão é a de que ou as comissões estão cumprindo uma tarefa que é do interesse do Executivo, ou esta tarefa lhe é indiferente. Nesta direção, a seção seguinte analisa o sistema de comissões brasileiro pela ótica da teoria distributiva. Apesar de existirem diversas razões para esta teoria não se aplicar diretamente ao caso brasileiro, adaptamos algumas de suas idéias centrais para mostrar como as comissões são úteis ao Executivo. Entretanto, como esta justificativa não parece suficiente para explicar o funcionamento das comissões no Congresso brasileiro, na terceira seção testamos o poder explicativo da teoria informacional. Adaptamos o modelo de Gilligan e Krehbiel (1987) para as instituições do Congresso brasileiro e derivamos algumas hipóteses que testamos com dados da legislatura 1995-1998. Resultados econométricos da análise da escolha de procedimentos (urgência versus não urgência) fornecem evidências empíricas de que as comissões no Brasil têm, de fato, pelo menos parcialmente, um papel informacional.

\section{Preponderância executiva em relação aos procedimentos legislativos}

Nesta seção descrevemos o poder de legislar do Executivo brasileiro, enfocando a sua habilidade em impor, mediante dispositivos institucionais, as suas preferências à legislação que esteja sendo decidida no Congresso. O objetivo não é ser exaustivo ou entrar nos detalhes, ${ }^{3}$ mas sim sublinhar o fato de o Executivo possuir suficientes meios e instrumentos para controlar as comissões. Tendo feito isto, estaremos em condição de explicar, nas próximas seções, qual o papel das comissões dentro do que estamos denominando de teoria da preponderância executiva.

Dois aspectos do processo de tomada de decisão no Congresso brasileiro são fundamentais para o entendimento de como o Executivo controla o Legislativo: primeiro, o poder de legislar garantido ao presidente pela Constituição; e, segundo, a centralização do poder decisório nas mãos dos líderes dos partidos no Congresso.

\section{Poderes constitucionais}

De acordo com Mainwaring e Shugart (1997), existem três categorias amplas de poderes constitucionais do presidente: (1) poderes legislativos próativos, ou seja, aqueles que permitem ao presidente legislar e estabelecer um novo status quo - o mais comum é a Medida Provisória (MP); (2) poderes legislativos reativos, ou seja, aqueles que permitem ao presidente bloquear a legislação e, 
como conseqüência, defender o status quo contra a maioria legislativa que queira mudá-lo — sobretudo vetos totais ou parciais; e (3) a capacidade do presidente de moldar ou até mesmo definir a agenda do Congresso, dado seu poder exclusivo de iniciar certos tipos de legislação.

O principal poder pró-ativo do Executivo garantido na Constituição brasileira é a capacidade do presidente de legislar através das Medidas Provisórias. Este dispositivo institucional o autoriza a promulgar prontamente uma nova legislação, sem a necessidade de aprová-la no Congresso. As Medidas Provisórias conferem ao presidente não só o poder de legislar, como também grande influência sobre a agenda do Congresso. Se o Congresso não bloquear uma Medida Provisória no prazo de 30 dias, ela automaticamente vai para o topo da agenda do Congresso, deslocando questões que vinham sendo discutidas prioritariamente. De acordo com a Constituição, a Medida Provisória só deve ser usada em situações específicas, mas na prática o Executivo tem feito uso indiscriminado deste dispositivo. Não só o número total de Medidas Provisórias tem crescido a cada legislatura nesta década, mas também muitas medidas vêm sendo reeditadas um grande número de vezes, já que o Congresso raramente as desafia. ${ }^{4}$ Sem considerar as Medidas Provisórias reeditadas e somente levando em conta aquelas que se transformaram em lei, o uso desse dispositivo tem sido alto, uma média de 3,5 MPs por mês no período 1995-1998, o que confere ao Executivo um poder expressivo na determinação da agenda do Legislativo, transferindo, assim, para a oposição a responsabilidade de construir uma maioria para rejeitar uma emenda ou decreto. Para que uma Medida Provisória permaneça em vigor não é necessário que a maioria do Congresso a aprove, mas apenas que uma maioria não a rejeite.

No que diz respeito ao poder reativo, o mais comum é o veto, que permite ao presidente defender o status quo, reagindo à tentativa da legislatura de mudá-lo. O mais usual é o veto total, por meio do qual o presidente pode rejeitar a proposta completa enviada pelo Congresso. Além de permitir ao presidente vetar proposições inteiras, a Constituição brasileira também permite vetos parciais. O presidente pode promulgar os artigos da proposta com os quais concorda, retornando ao Congresso, para reconsideração, somente as partes vetadas. Shugart e Carey (1992, p. 134) lembram que "embora seja tecnicamente um poder negativo, o veto parcial permite ao presidente dissecar a legislação e criar pacotes finais que são mais aceitáveis ao Executivo [...] como resultado o poder presidencial se torna mais flexível e mais potente do que seria somente com o veto total". Talvez por este motivo o presidente não tenha usado o veto total durante o período analisado: todos os 83 vetos registrados foram a partes específicas de uma proposta. Cabe notar, também, que embora a Constituição de 1988 tenha tornado relativamente fácil para o Legislativo reverter um veto presidencial, dado que isto requer somente maioria absoluta, o Congresso brasileiro não fez uso desse dispositivo institucional ao longo da legislatura 1995-1998.

Além da Medida Provisória e do poder de veto, a Constituição brasileira define alguns temas sobre os quais o Executivo tem o poder exclusivo de iniciar legislação. Somente o presidente pode introduzir propostas que digam respeito a problemas orçamentários e de administração pública, por exemplo. Em se tratando de leis orçamentárias, embora uma maioria no Congresso tenha o direito de propor emendas às propostas que foram introduzidas pelo presidente, esta maioria só pode fazer isto se essas emendas forem compatíveis com o plano de orçamento plurianual elaborado pelo Executivo, bem como com a Lei de Diretrizes Orçamentárias. Além disso, o Congresso não pode autorizar despesas que excedam as receitas orçamentárias. $\mathrm{Na}$ prática, estas regras permitem ao presidente preservar o status quo em questões orçamentárias simplesmente pela não introdução de uma proposta.

Do total de 805 propostas que tramitaram no Congresso brasileiro entre 1995 e 1998, 648 (80,49\%) foram iniciadas pelo Executivo, 141 (17,51\%) foram iniciadas pelo Legislativo e apenas 16 (1,98\%) pelo Judiciário. ${ }^{5}$ O tempo médio para uma proposta do Executivo ser sancionada pelo Congresso foi de 183 dias; no caso das propostas iniciadas pelo Legislativo e pelo Judiciário, este prazo estendeu-se para 1.194 e 550 dias, respectivamente. ${ }^{6}$ 
A situação assim descrita mostra que há uma clara divisão de trabalho dentro do Congresso determinando quem legisla sobre cada tema. Das 648 propostas iniciadas pelo Executivo, 484 $(74,69 \%)$ são sobre temas ligados diretamente à economia, $110(16,97 \%)$ são administrativas, e só $54(8,33 \%)$ são relacionadas a temas políticos ou sociais. Por outro lado, das 141 propostas iniciadas pelos próprios parlamentares, 79 (56,02\%) são das áreas política e social, 42 (29,78\%) são administrativas e $20(14,18 \%)$ são sobre a área econômica. Observa-se, assim, que a área de atuação do Congresso é restringida pela agenda do presidente.

Outro instrumento importante que o Executivo pode utilizar para interferir na tramitação de uma proposta no Congresso é o pedido de urgência, equivalente à discharge petition no Congresso americano. Quando um pedido de urgência é feito para uma proposta, a comissão tem somente duas sessões para examiná-la e votá-la antes de mandá-la para o plenário. Na prática, este prazo é muito curto e as comissões dificilmente conseguem examinar e se posicionar em relação a uma proposta que tenha recebido um pedido de urgência. De acordo com o regimento da Câmara (Art. 54), o pedido de urgência pode ser feito por três atores do Legislativo, além do presidente: (a) dois terços da Mesa Diretora; (b) um terço dos membros do plenário ou líderes que representem este número; (c) dois terços dos membros da comissão relevante. Por sua vez, uma proposta que estiver sob pedido de urgência só pode receber emendas da comissão, de um quinto dos membros da Câmara ou dos líderes que representem esse número. Ao contrário da discharge petition no Congresso americano, o pedido de urgência é amplamente utilizado no Congresso brasileiro.

De 805 propostas promulgadas entre 1995 e 1998, $294(36,52 \%)$ receberam pedido de urgência e $511(63,34 \%)$ tramitaram normalmente. A maioria das propostas que receberam pedido de urgência foi iniciada pelo Executivo — 237 (80,61\%), de um total de 294 propostas —, mas a maioria dos pedidos foi feita pelo próprio Congresso $70,40 \%$ deles, contra $29,60 \%$ de responsabilidade do Executivo. $\mathrm{O}$ que significa que os próprios deputados se abstêm de discutir e decidir sobre grande parte da nova legislação nas comissões.

Pedidos de urgência foram feitos principalmente para propostas sobre temas econômicos $(49,97 \%)$ e administrativos (28,91\%); temas sociais $(19,38 \%)$ e políticos $(2,72 \%)$ têm recebido menos pedidos de urgência. Em geral, pode-se dizer que quando o Legislativo pediu urgência para uma proposta, isto foi feito de acordo com os interesses do Executivo. A taxa de aprovação de legislação com origem no Executivo está altamente associada com o pedido de urgência. Dado este fato, o pedido de urgência será um dos pontos focais da nossa análise nas próximas seções.

Esta descrição parcial do funcionamento do Congresso brasileiro mostra que se o partido do presidente (ou a coalizão governista) dispuser de uma maioria na Câmara, o Executivo pode contar com os líderes do partido para requerer urgência para as propostas que mais lhe interessarem ver aprovadas. A combinação de Medidas Provisórias, vetos e pedidos de urgência fornece ao Executivo um poderoso conjunto de instrumentos para controlar a agenda do Congresso, bloqueando legislação que não lhe interesse e promovendo aquelas consideradas prioritárias.

Organização interna do Congresso brasileiro

Os instrumentos e normas constitucionais discutidos acima não são os únicos fatores que colocam o Executivo em uma posição privilegiada em relação ao Congresso. A centralização do processo de tomada de decisão dentro do Congresso também serve a este propósito. As regras internas da Câmara garantem aos líderes dos partidos na Mesa Diretora e no Colégio dos Líderes um papel central na condução do processo legislativo e na definição do sistema de comissões.

De maneira geral, é prerrogativa dos líderes dos partidos nomear, assim como substituir, a qualquer momento, os membros das comissões (Art. 10). Não há restrições quanto ao tempo de permanência dos deputados nas comissões. Aparentemente, existe uma auto-seleção por parte dos deputados, porém, há evidências (que serão discutidas mais adiante) de que os líderes dos partidos interferem significativamente no processo de no- 
meação dos integrantes das comissões. Como mostraremos, estas apresentam uma alta rotatividade. Os deputados mudam de comissão freqüentemente, não só a cada novo ano legislativo, como também em um mesmo ano. Além disso, demonstraremos que o Executivo, através dos líderes do partido ou coalizão governista, manipula as nomeações de certas comissões para colocar nelas um número estratégico de membros fiéis aos seus interesses.

Um bom exemplo do poder exercido pelo Executivo por meio dos líderes dos partidos que the dão sustentação política no Congresso ocorreu na Comissão de Trabalho da Câmara, durante a votação do projeto de lei do deputado Paulo Paim (PTRS) que previa o aumento do salário mínimo para R\$ 180,00. Conforme noticiou a Agência Estado (19/ 5/1999), "a vitória da base governista foi apertada e conquistada graças a uma manobra de última hora dos governistas, que substituíram dois deputados titulares da comissão - Wilson Braga (PFL) e Ricardo Noronha (PMDB) - por dois suplentes, João Ribeiro (PFL) e Pinheiro Landim (PMDB)."

Com o objetivo de saber se os deputados que entraram nessa comissão eram mais fiéis ao governo do que os que saíram, comparamos os seus respectivos índices de lealdade ao governo. Estes índices foram construídos a partir das votações nominais no plenário da Câmara de 1995 a 1998 e variaram de 7,75 negativos, para o deputado que menos cooperou com o governo, a 8,52 positivos, para o deputado que mais cooperou (ver explicação mais detalhada deste índice mais adiante no texto). Dos parlamentares titulares que saíram, Wilson Braga obteve o índice de lealdade de 0,09 (localizado entre os 20\% que menos cooperaram com o governo). Dos suplentes que entraram, João Ribeiro obteve o índice de 6,86 e Pinheiro Landim, de 7,70, situando-se, respectivamente, entre os $40 \%$ e os $20 \%$ dos parlamentares que mais cooperaram com o Executivo. Este fato é uma forte indicação de que o Executivo atua de forma estratégica, junto com os líderes do partido (ou coalizão) governista, substituindo membros das comissões que lhe são menos leais com o objetivo de assegurar a vitória de seus interesses (Leoni, 2000).

De acordo com as regras internas da Câmara, o processo de composição das comissões perma- nentes deve levar em conta a proporção de representantes de cada partido na Câmara (Art. 25 S 1 ). Portanto, partidos maiores terão um número maior de membros em cada comissão. Cada deputado só pode participar de uma comissão como membro titular e não há uma regra de senioridade para os postos hierárquicos da comissão, como ocorre nos EUA. Os postos de presidente, vice-presidente, secretário e relator não são cativos. Embora, oficialmente, estas posições sejam escolhidas por voto secreto e maioria absoluta dos votos dos membros da comissão a cada dois anos, na prática elas são determinadas pelos líderes dos partidos.

Outro indicador da centralização do processo de tomada de decisão no Congresso brasileiro é a maneira pela qual os projetos são distribuídos às comissões. O presidente da Mesa Diretora tem o direito de determinar quais comissões irão analisar e dar um parecer oficial sobre cada projeto específico. Esta regra tem conseqüências importantes porque, segundo o regimento da Câmara, quando um projeto é analisado por mais de três comissões permanentes, automaticamente uma nova comissão especial deverá ser criada para analisá-lo. Dado que os líderes dos partidos têm poder para influenciar a composição das comissões especiais, pode ser estrategicamente interessante para eles mitigar o poder das comissões permanentes em casos específicos. ${ }^{7}$

A maioria dos elementos discutidos nesta seção indica que o poder das comissões do Congresso brasileiro tem uma base institucional muito fraca. É verdade que a Constituição de 1988 também concedeu às comissões permanentes um instrumento que potencialmente as dotaria de uma significativa fonte de poder: o poder terminativo ou conclusivo. Por meio deste instrumento as comissões podem aprovar uma proposta diretamente, sem que seja necessário submetê-la ao plenário. Claramente, a intenção original desta regra era fortalecer as comissões dentro do Congresso. Porém, na prática, o poder conclusivo não teve este efeito. Das 805 propostas aprovadas entre 1985 e 1998, 207 (25,20\%) foram indicadas pelo presidente da Câmara como passíveis de serem aprovadas por poder conclusivo pelas comissões. No entanto, as comissões somente fizeram uso 
deste direito em $106(13,16 \%)$ casos, sendo que apenas $71(8,81 \%)$ propostas realmente foram aprovadas pelas comissões sem emendas do plenário. ${ }^{8}$ Uma das razões pelas quais as comissões não têm feito uso mais freqüente deste procedimento é o alto número de pedidos de urgência. Das 207 propostas suscetíveis de serem aprovadas diretamente pelas comissões, 96 receberam pedidos de urgência. Além disso, suspeitamos que grande parte daquelas propostas que foram aprovadas por poder conclusivo era matéria não controversa.

Para terminar esta seção, deve ser mencionado outro meio amplamente usado pelo Executivo para fazer prevalecer suas preferências no Congresso. Alguns autores argumentam que no Brasil a carreira legislativa não é particularmente atrativa (Bernardes, 1996; Figueiredo e Limongi, 1996), apresentando-se, em geral, como um passo intermediário a caminho de postos mais desejáveis no Poder Executivo, nos nível federal, estadual e/ou municipal. Segundo estes autores, isto ocorre porque diversos cargos importantes no país não são eletivos, sendo a nomeação de seus titulares fortemente influenciada pelo Executivo. Além disso, o Executivo no Brasil controla uma grande variedade de recursos, tais como crédito, execução de emendas individuais dos parlamentares, concessões de televisão e rádio, licitações etc., utilizando estes tipos de favores como meio de obter apoio e votos para seus projetos no Congresso.

\section{Uma adaptação da teoria distributiva para a teoria da preponderância executiva}

$\mathrm{Na}$ seção anterior foi mostrado que o Executivo, no Brasil, possui amplos poderes para defender seus interesses no Congresso. Foi indicado que as comissões parlamentares aparentam ter muito pouco poder e cumprem somente papéis secundários no processo legislativo. $O$ direito de propor legislação, o poder de retirar propostas das comissões mediante o pedido de urgência e o poder de vetar legislação aprovada pelo plenário asseguram ao Executivo meios significativos para perseguir os seus interesses. Nesta seção examinamos a teoria distributiva para ver se suas teses e instrumentos podem nos ajudar a compreender melhor o funcionamento do sistema de comissões no Brasil. A idéia é mostrar que as comissões cumprem um papel importante em um Legislativo dominado pelo Executivo, similar ao papel que desempenham em muitos sistemas parlamentaristas, pois, conforme observaram Shepsle e Bonchek (1997, p. 472):

\footnotetext{
Se as comissões não tivessem nenhuma autoridade, ou se qualquer autoridade que porventura tivessem levasse a pouco impacto sobre as políticas finalmente aprovadas no Congresso ou no sistema político, então praticamente a única coisa que o membro de uma comissão poderia fazer seria listar sua participação em seu currículo junto com sua associação a outros clubes e sociedades honorárias.
}

O primeiro ponto a destacar é que a teoria distributiva, tal como formulada por Shepsle e Weingast (1987) e Weingast e Marshall (1988), não se aplica diretamente ao Congresso brasileiro, devido ao baixo poder institucional nas comissões, como foi mostrado na seção anterior. Pela teoria distributiva, o sistema de comissões levaria a uma divisão do poder de decisão em jurisdições dentro das quais seus membros teriam significativas vantagens em impor suas preferências, mesmo que estas fossem distantes dos interesses da maioria do plenário. Pelo que foi mostrado acima, as comissões brasileiras claramente não têm poder para fazer valer suas preferências. Em particular, a teoria distributiva requer que os parlamentares tenham a capacidade de se auto-selecionar para as comissões de seu interesse e de lá permanecer e não ser substituído contra sua vontade. Este não é o caso no sistema de comissões brasileiro. Embora os deputados muitas vezes consigam ser alocados nas comissões de sua preferência, não há nenhuma garantia de que isso vá acontecer ou de que, uma vez nessa comissão, não venham a ser transferidos para outra quando assim for conveniente ao líder do partido. Como mostraremos mais adiante, com base em dados empíricos referentes à legislatura 1995-1998, as comissões brasileiras têm um alto 
nível de rotatividade. Apresentaremos também algumas evidências que sugerem que essa rotatividade se dá, muitas vezes, contra a vontade do deputado que é colocado ou tirado de uma comissão pelos líderes dos partidos. $O$ ponto a ser sublinhado é que, se isto está ocorrendo, uma das principais condições da teoria distributiva está sendo violada e, portanto, esta explicação não se aplica ao caso em questão. No entanto, também iremos mostrar, na próxima seção, que a maioria das comissões constituídas ao longo da legislatura 1995-1998 tinha uma composição tal que seu membro mediano apresentava um alto índice de lealdade à posição do Executivo, o que sugere que o Executivo usou seus poderes legislativos para fazer com que a composição das comissões lhe fosse favorável. Surge, portanto, a questão: o que as comissões podem fazer pelo Executivo que justifique que este despenda esforços para controlar sua composição? Não existe uma resposta óbvia para esta questão; afinal, as comissões não possuem poder de agenda, poder de veto ou qualquer outra fonte significativa de poder para afetar a legislação em exame.

Para tentar responder esta pergunta nos baseamos no trabalho seminal de Shepsle e Weingast (1987), que argumenta que o poder de proposta e o poder de barrar propostas na comissão (gate-keeping power) não são suficientes para justificar o poder exercido pelas comissões no Congresso dos EUA. Segundo estes autores, a chave do poder das comissões parlamentares norte-americanas é a oportunidade que têm de vetar uma proposta após ela ter sido mudada pelo plenário, o veto ex-post. Isto pode ser visto no painel $\mathrm{I}$ da Figura 1, que segue o exemplo de Shepsle e Weingast, onde temos uma legislatura composta de três pessoas, uma das quais, $C$, tem os poderes de uma comissão. A figura mostra o ponto de status quo, SQ, assim como todos os pontos que são capazes de derrotar o status quo por uma maioria de dois membros, o conjunto $W(S Q)$. A comissão pode propor a legislação $B$, por exemplo, apresentada no painel II junto com o conjunto de pontos que pode derrotá-la, $W(B)$. Uma vez que a comissão mande a proposta $B$ para o plenário, esta pode ser modificada e movida para algum ponto que a comissão considere pior do que
$B$ ou para o próprio status quo. Em particular, seria de esperar que o plenário alterasse a proposta para qualquer ponto dentro de $W(S Q) \cap W(B)$, tal como o ponto $A$. No trabalho de Shepsle e Weingast, a comissão é capaz de dissuadir estas modificações na proposta porque tem o direito de vetar a nova proposta após ela ter sido analisada pelo plenário, quando a legislação é enviada à comissão de conferência (conference committee) que compatibiliza as propostas do Senado e da Câmara. Como a comissão pode vetar uma proposta como $A$ nesta instância, o plenário irá prever esta ação e, portanto, não mudará a proposta original para nenhum ponto que seja pior para a comissão do que o status quo. Desta forma, muito da deferência do plenário para com as comissões, reconhecida pela literatura, deriva, na realidade, das regras institucionais que determinam a seqüência pela qual passam as propostas.

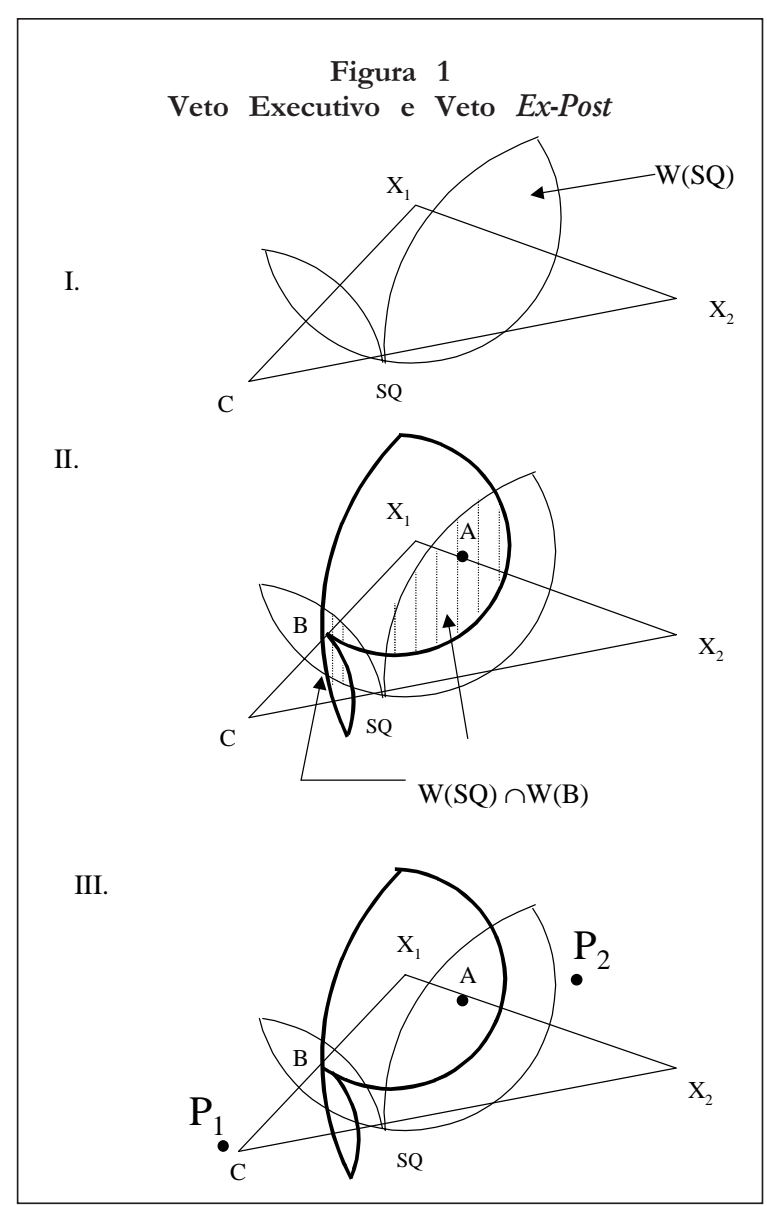


No caso brasileiro, porém, não há uma comissão de conferência ou qualquer outra instância na qual a comissão tenha oportunidade de vetar a legislação. Portanto, uma vez que a proposta $B$ é enviada ao plenário, ela poderá ser alterada e haverá uma alta probabilidade de a comissão se ver prejudicada. Além disso, dado o fato de que pedidos de urgência são freqüentes no Congresso brasileiro, a comissão não tem nem a opção defensiva de impedir que a proposta vá a plenário. Será, portanto, que as comissões são irrelevantes em todo este processo? Devido aos amplos poderes do Executivo no processo legislativo, é necessário incorporá-lo à análise para responder esta pergunta. Se a comissão tem preferências que são distantes das do Executivo, então a resposta é afirmativa. Suponha, por exemplo, que o Executivo tem preferências no ponto $P_{2}$ no painel III. Então, o Executivo pode propor legislação que seja distante do ponto preferido da comissão, tal como no ponto $A$, pedir urgência para tirar a proposta $\mathrm{da}$ comissão e vê-la aprovada por uma maioria $\left\{x_{1}, x_{2}\right\}$. $\mathrm{O}$ fato de os pedidos de urgência serem comuns e de o Executivo geralmente ter o apoio de uma maioria na Câmara indica que este deve ser o caso para muitas propostas. ${ }^{10}$

Se, por outro lado, a comissão tiver sua composição manipulada para que seu membro mediano tenha alta lealdade ao Executivo, como seria o caso se $P_{1}$ representasse a posição preferida do Executivo, então poder-se-ia argumentar que as comissões têm um papel a desempenhar. Uma proposta $B$ da comissão poderia ser derrotada por qualquer proposta em $W(S Q) \cap W(B)$ - por exemplo, pela proposta $A$. Porém, como a proposta pode ser vetada pelo presidente, é como se a comissão possuísse um veto ex-post. $\mathrm{Na}$ realidade, este veto não seria exercido pela comissão em si, mas como a comissão tem preferências muito próximas das do Executivo, o argumento procede como se a comissão tivesse este poder. Se o plenário mudasse a proposta $B$ para o ponto $A$, o Executivo iria vetá-la e o status quo prevaleceria. Como todos os membros do plenário são racionais e prevêem esta ação, eles não tentariam derrotar $B$. Em algumas circunstâncias pode ser possível para uma maioria do plenário reverter o veto do presi- dente. No painel III este poderia ser o caso, dado que $A$ é preferido ao status quo por uma maioria $\left\{x_{1}, x_{2}\right\}$. Porém, o Executivo tem o poder de vetar somente partes da proposta, de modo que ele poderia manobrar a proposta vetada para um ponto que não pode ser derrotado pelo status quo.

$\mathrm{O}$ argumento acima é somente um exemplo e os resultados em casos específicos dependem das preferências relativas dos atores. $O$ ponto central do argumento é mostrar que há, de fato, algo que as comissões podem fazer pelo Executivo quando as suas preferências são próximas. A comissão, fortalecida pela ameaça de veto presidencial, é capaz de impedir que legislação contrária aos interesses do Executivo chegue ao plenário. Deve ser reconhecido, porém, que se este é o único papel desempenhado pelas comissões, então elas são atores secundários no processo legislativo. Intuitivamente, parece que a mera existência de um sistema tão complexo e ativo como se observa no Congresso brasileiro indicaria um papel mais importante. $\mathrm{Na}$ próxima seção investigamos se é possível encontrar um papel informacional para as comissões.

\section{O papel informacional exercido pelas comissões na Câmara dos Deputados}

\section{O modelo}

Como a teoria distributiva oferece poucas justificativas para explicar a existência e o funcionamento do sistema de comissões brasileiro, esta seção analisa se a abordagem da teoria informacional é capaz de gerar melhores resultados. $\mathrm{O}$ modelo apresentado aqui é baseado em Gilligan e Krehbiel (1987), adaptado às regras específicas do Congresso brasileiro com o objetivo de explicitamente incluir o Executivo como ator relevante. A principal motivação por trás do modelo é a idéia de que o sistema de comissões existe para proporcionar ganhos informacionais para o plenário e o Executivo, por meio de subgrupos que se especializam em tópicos específicos. Esta especialização permite que as comissões adquiram informação sobre as verdadeiras conseqüências de uma proposta que será considerada pelo plenário. Decerto, as comissões têm incentivos para, estrategicamente, distor- 
cer a informação que possuem de modo a obter um ganho à custa do plenário. Porém, sob certas circunstâncias o ganho informacional para o plenário, advindo da redução da incerteza, pode ser suficiente para compensar essa perda. Desta forma, o plenário pode conceder poderes especiais às comissões, tais como closed rules (Gilligan e Krehbiel, 1987) ou poderes de veto (gate-keeping power), como incentivos para que se especializem e revelem mais informações. Podese argumentar que em muitos casos as regras e instituições observadas em legislativos se desenvolveram, ao menos em parte, no sentido da captura de ganhos informacionais.

A seguir será feita uma descrição do nosso modelo informacional para o Congresso brasileiro. O modelo formalizado é apresentado no Apêndice ao final do artigo; aqui daremos uma descrição intuitiva de suas premissas, sua lógica e de suas hipóteses derivadas. A premissa central do modelo foi apresentada no parágrafo anterior. Existe incerteza a respeito das conseqüências de uma proposta uma vez que ela for aprovada e implementada. Como todos os agentes são avessos ao risco, todos têm a ganhar se a proposta for examinada e suas conseqüências potenciais tornadas claras. Porém, existem custos de especialização por parte dos deputados, assim como existem custos de se examinar a proposta. Sendo assim, o plenário oferece incentivos para que os deputados, em suas comissões específicas, se disponham a arcar com estes custos. Um dos incentivos usados é a concessão de poderes especiais às comissões, como o poder de veto e o poder de alterar as propostas. Por meio destes poderes os membros das comissão podem influenciar o desenho da proposta e, com isto, obter para si ganhos distributivos. O plenário sabe que os membros das comissões agirão desta forma, porém encara esta perda distributiva como um custo devido à assimetria de informação que será compensado com os ganhos advindos da redução da incerteza.

No Congresso brasileiro, o plenário e/ou o Executivo podem escolher se querem deixar a comissão examinar uma proposta ou se querem pedir urgência e enviá-la diretamente para ser votada no plenário. A estrutura desta decisão e os ganhos líquidos de cada escolha estão representados na Figura 2. Caso a proposta tramite com pedido de urgência, a comissão não descobre nem transmite qualquer informação que possa reduzir as incertezas. Em compensação, a proposta é votada rapidamente e as partes não arcam com custos de espera. Este é o custo que plenário, Executivo e membros da comissão arcam por ter de esperar que uma proposta seja examinada ao invés de ser diretamente votada.

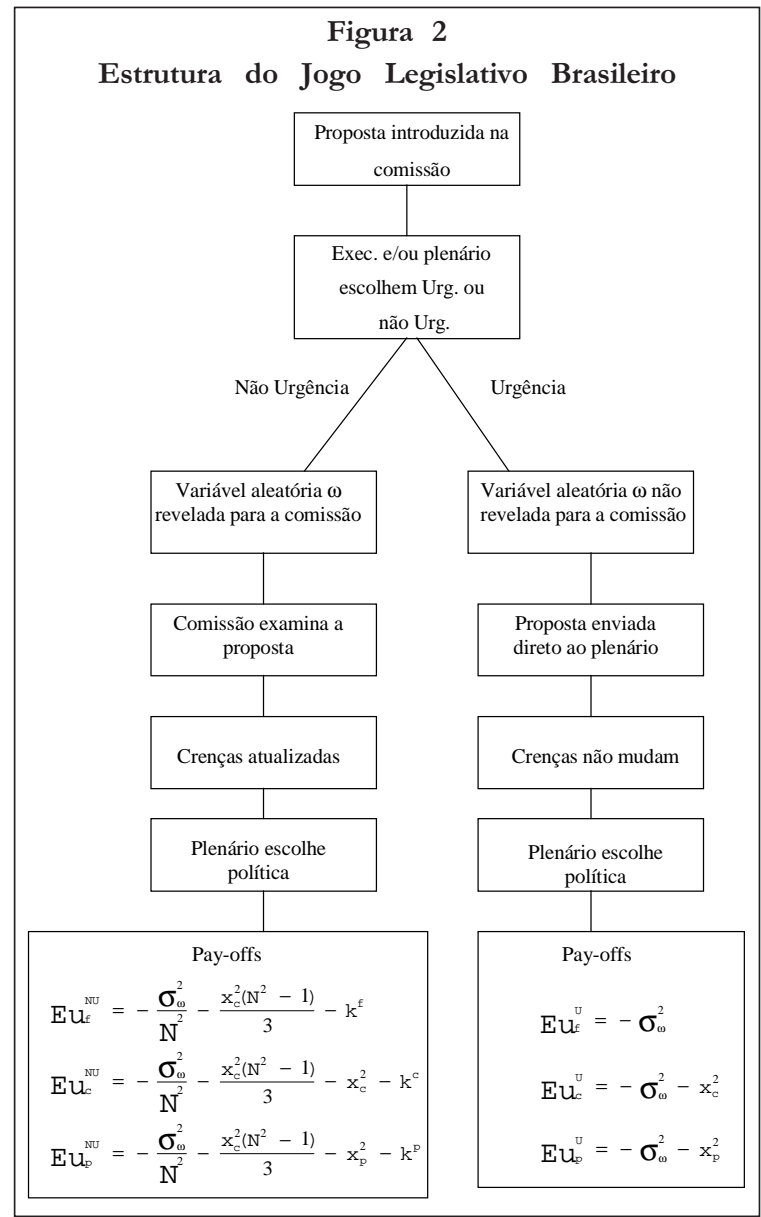

Naturalmente, estes custos variam de acordo com o conteúdo de cada proposta, pois dependem da urgência de cada ator em vê-la implementada. Se a urgência não for requisitada, a comissão examina a proposta e manda uma mensagem para o plenário a respeito das conseqüências que tal proposta proporcionará se for implementada. Como a comissão tem a sua própria preferência, ela não mandará uma men- 
sagem necessariamente verdadeira. $\mathrm{O}$ jogo descrito no Apêndice leva em conta o interesse de cada ator - comissão, plenário e Executivo - e busca achar um conjunto de estratégias para cada um, de tal forma que cada qual esteja fazendo o melhor que pode dado o que os outros atores estejam fazendo. Cada ator sabe qual o interesse dos outros e sabe que os outros conhecem o seu. Todos sabem que os outros estão agindo estrategicamente dentro das regras do jogo. O resultado final é um equilíbrio em que nenhuma das partes quer mudar sua estratégia dado o que os outros estão fazendo.

O jogo é composto de duas partes. Primeiro, o plenário e o Executivo escolhem se haverá urgência ou não. Em seguida, a comissão manda uma mensagem para o plenário que vota a proposta. Como sempre, nestes jogos, começa-se com o estágio final. O equilíbrio a que chegamos nesta parte envolve as seguintes estratégias quando a urgência não é pedida: a comissão examina a proposta e descobre suas verdadeiras conseqüências; a mensagem enviada pela comissão para o plenário não diz exatamente quais são estas conseqüências, porém indica, sem mentir, um conjunto de possíveis conseqüências próximas dentre as quais se encontra a verdadeira. O plenário, neste equilíbrio, acredita na mensagem da comissão e com base nesta informação escolhe a política que considera a melhor. Quando a comissão mandou a mensagem, ela previu que o plenário agiria desta forma e a mensagem foi especificamente construída para que este comportamento por parte do plenário levasse à melhor proposta possível para a comissão, dadas as condições do jogo. Caso a urgência tenha sido pedida, a comissão não examina a proposta e, portanto, qualquer mensagem que envie ao plenário será interpretada como sendo isenta de informação. O plenário, então, vota a proposta simplesmente com base na informação que já possui. $\mathrm{Na}$ primeira parte do jogo, que examinamos por último, o plenário e o Executivo olham para a frente e determinam qual será o resultado para cada um no caso da urgência ser pedida ou não. Com base nesta avaliação eles determinam se fazem ou não o pedido de urgência.

No Apêndice mostramos um exemplo deste jogo atribuindo valores arbitrários para as prefe- rências de cada ator. As Figuras 3 e 4 (descritas e apresentadas no Apêndice) mostram os equilíbrios para os casos de urgência e não urgência. Sem levar em conta o custo de espera, o resultado sem urgência é sempre melhor do que com urgência para todas as partes envolvidas. Porém, levando em conta o custo de espera, e dependendo do tamanho deste, o resultado sem urgência pode vir a ser pior do que o com urgência para alguns atores. Estas relações são mostradas nos Gráficos 1, 2 e 3. Pode-se notar, nestes gráficos, que a variável crucial é a distância entre a preferência mediana da comissão e a do plenário, ou seja, $x_{c}$, que está localizado no eixo horizontal. Abstraindo momentaneamente o custo de espera, para valores pequenos de $x_{c}$ todos os atores preferem o procedimento sem urgência. À medida que $x_{c}$ aumenta, os resultados sem urgência caem mais rápido do que os resultados com urgência, de modo que eventualmente se chega a um ponto onde a urgência se torna preferível. O custo de espera pode acelerar a chegada a este ponto. Nos gráficos, um aumento do custo de espera significa um deslocamento para baixo da curva de resultados sem urgência. Nestes gráficos foi atribuído um pequeno custo de espera, porém é possível que este seja tão grande que a curva sem urgência seja sempre abaixo da curva com urgência. Quando este for o caso, esperamos observar o pedido de urgência seja qual for a composição da comissão. A intuição por trás dos gráficos é a de que quanto mais coincidentes forem as preferências do plenário e da comissão, ou seja, quanto menor for $x_{c}$, maior será o nível de informação verdadeira transmitido pela comissão e, portanto, maior será o ganho de redução de incerteza para todas as partes.

As considerações acima geram algumas hipóteses que deverão ser confirmadas se de fato o Congresso brasileiro e seu sistema de comissões forem afetados por considerações informacionais tal como modelado nesta seção. A variável-chave neste modelo é $x_{c}$, que mede a distância entre a preferência mediana da comissão e a preferência mediana do plenário. Contudo, se considerarmos o jogo de uma forma mais ampla, levando em conta o estágio precedente, quando a composição da comissão é determinada, podemos considerar $x_{c}$ 

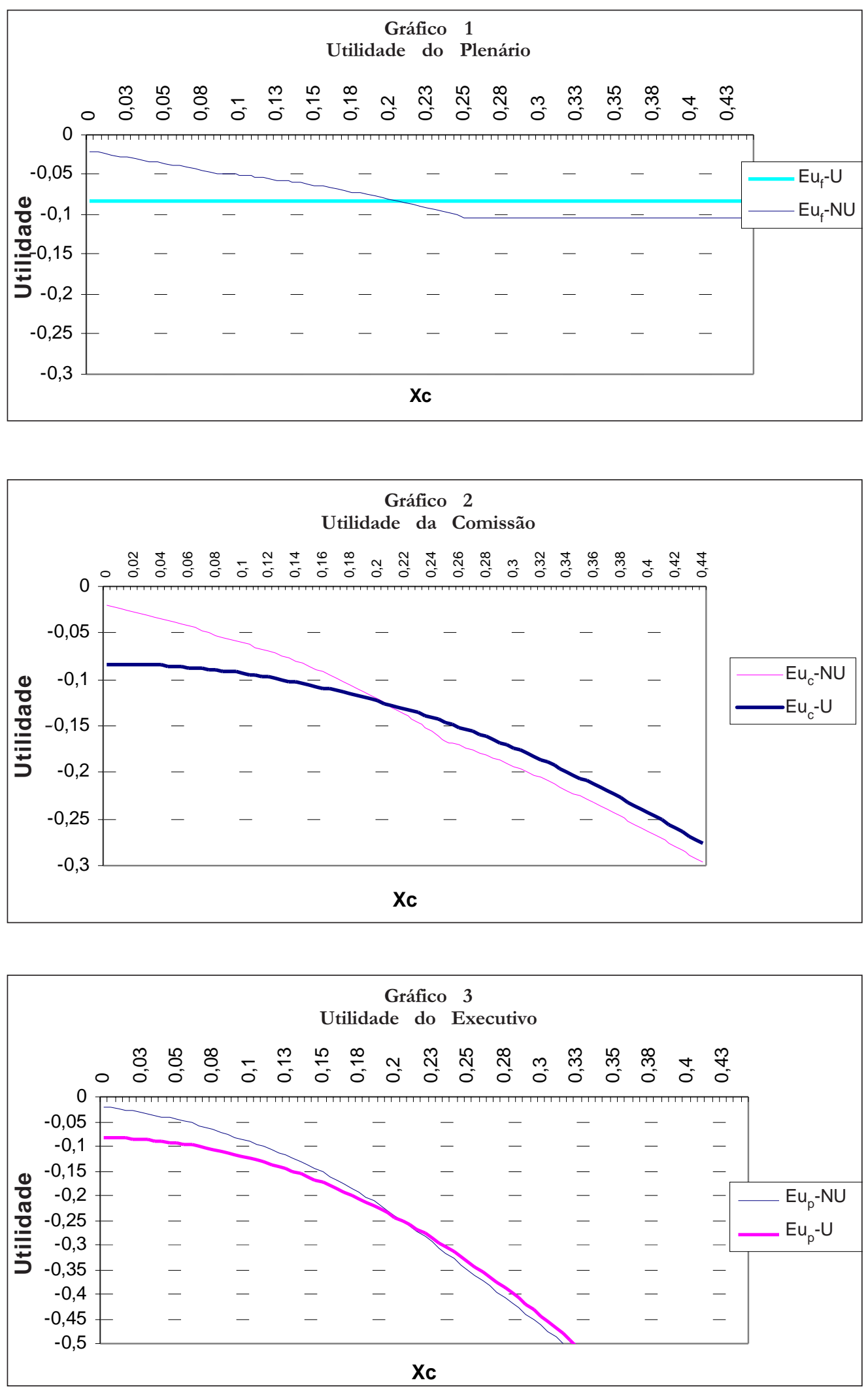
como sendo endogenamente determinado. Todos os atores - plenário, membros das comissões, partidos e Executivo - têm interesse em que, ceteris paribus, a comissão seja altamente representativa do plenário como um todo. Isto é, se de fato o sistema de comissões se desenvolveu como meio de proporcionar ganhos de informação inerentes à especialização, então não seria de se esperar que as comissões fossem compostas por membros medianos com preferências extremas (preference outliers), tal como presumido pela teoria distributiva. Podemos, portanto, deduzir a primeira hipótese a ser testada na próxima seção:

Hipótese 1 - Comissões representativas. As comissões tenderão a ser representativas das preferências do plenário como um todo e não a ter seus membros medianos com preferências extremas.

A respeito da escolha entre urgência $\left(P^{U}\right)$ e não urgência $\left(P^{N U}\right)$ para determinada proposta, o modelo gera as seguintes hipóteses:

Hipótese 2 - Urgência. Quanto mais extrema for a preferência mediana da comissão, maior será a probabilidade de um pedido de urgência, ceteris paribus.

Hipótese 3 - Custos de espera. Quanto maior for o custo de espera de determinada proposta para os membros do plenário e o Executivo, maior será a probabilidade de um pedido de urgência, ceteris paribus.

Hipótese 4 - Incerteza. Quanto maior for a incerteza envolvendo determinada proposta, menor será a probabilidade de um pedido de urgência, ceteris paribus.

As Hipóteses 1, 2 e 3 saem diretamente do modelo e da discussão acima, porém a Hipótese 4 merece alguns comentários. Teorias informacionais estão baseadas no fato de que a legislação pode levar a resultados finais bastante diferentes das intenções originais das políticas, de modo que a especialização por parte das comissões pode beneficiar a todos os atores, já que estes são, em geral, avessos ao risco. No entanto, nem todas as propostas são igualmente suscetíveis à incerteza. Muitas propostas têm conseqüências claras e previsíveis, de modo que há pouco potencial para ganhos informacionais. Nestes casos, considerações distributivas serão mais importantes e a ur- gência tenderá a ser preferida, ceteris paribus, para reduzir os custos de espera.

\section{Testes empiricos do modelo informacional}

A primeira hipótese, comissões representativas, pode ser testada comparando-se as preferências dos membros das comissões às preferências do plenário como um todo. A literatura sobre composição de comissões contém uma grande variedade de tais testes. Cada uma das teorias gera diferentes hipóteses sobre a composição das comissões e estas têm sido exaustivamente testadas. ${ }^{11}$ Neste trabalho, adotamos a metodologia sugerida em Groseclose (1994b), que compara a preferência mediana da comissão às medianas geradas através de uma simulação de Monte Carlo. Esta simulação seleciona aleatoriamente $20 \mathrm{mil}$ comissões do plenário, permitindo, assim, gerar uma distribuição que nos mostra qual a probabilidade de observarmos cada resultado possível da mediana, supondo que sua composição foi determinada aleatoriamente. Com isto podemos determinar se a mediana da comissão real é representativa do plenário ou se se trata de uma preferência extrema.

Para termos uma medida das preferências dos deputados tivemos de criar nosso próprio índice, já que no Brasil só existe um índice criado por um grupo de interesse. ${ }^{12}$ Para fazer isto usamos dados de todas as votações nominais no plenário da Câmara dos Deputados no período de 1995 a 1998, classificando os votos como sendo favoráveis ou contra a posição defendida pelo Executivo. ${ }^{13}$ Quanto maior for o índice, mais favorável à posição do Executivo será o deputado, tratando-se, assim, de um índice de lealdade ao Executivo. Como as preferências por temas específicos tendem a ser altamente correlacionadas com este índice mais geral, justifica-se o seu uso como uma proxy. ${ }^{14}$

Para implementarmos o teste de composição das comissões tivemos de levar em conta o alto nível de rotatividade das comissões brasileiras. Embora, em geral, haja um núcleo de membros estáveis em cada comissão, a composição total das comissões tende a variar freqüentemente, até entre uma reunião e a seguinte. Portanto, ao contrário dos testes para o Congresso dos EUA, não pudemos seguir a premissa de que cada comissão tem uma 
composição estática ao longo de cada legislatura. Determinamos, portanto, a preferência mediana para cada vez que a comissão se reuniu ao longo do período 1995-1998 e plotamos estes valores seqüencialmente para três comissões selecionadas nos Gráficos 4, 5 e $6 .{ }^{15}$ Neles também indicamos a preferência mediana do plenário, assim como os pontos que separam os $10 \%$ dos membros com preferências mais altas dos $10 \%$ com preferências mais baixas. Além disso, os gráficos mostram a distância que separa os $10 \%$ dos deputados imediatamente acima da preferência mediana do plenário dos 10\% imediatamente abaixo. Estes pontos são obtidos pela simulação de Monte Carlo e servem de níveis críticos contra os quais podemos comparar as medianas das comissões reais para determinar se são representativas ou extremas. ${ }^{16}$ Comissões com medianas acima (em valores absolutos) dos valores críticos mais extremos indicam comissões compostas de preferências extremas (preference outliers). Já comissões com preferências próximas à mediana do plenário indicam comissões representativas.

O primeiro ponto a notar nos gráficos é a alta variação da mediana de cada comissão ao longo do tempo. Algumas comissões são relativamente estáveis ao longo das legislaturas, porém a maioria delas apresenta fortes flutuações. É bastante claro que as medianas tendem a mudar no momento que cada novo ano legislativo começa, em fevereiro. Mas, em alguns casos, as medianas flutuam até mesmo dentro do mesmo ano e de um encontro para o outro. Existem casos de mudanças bruscas nas medianas, que passam de níveis significativamente acima da mediana do plenário para níveis significativamente abaixo desta, como, por exemplo, a Comissão de Agricultura e Política Rural (CAPR). ${ }^{17}$

Para compreender o que motiva este alto nível de rotatividade nas comissões, mandamos questionários para uma grande amostra dos deputados em 1999. O principal objetivo era descobrir se a mudança de comissão era motivada por vontade própria do parlamentar, ou era forçada pelos líderes dos partidos, que detêm poderes regimentais para, estrategicamente, manipular a composição das comissões, a fim de melhor influir no resultado da votação de determinadas propostas. A evidência encontrada indicou que ambas as forças atuam sobre a composição das comissões. ${ }^{18}$ Muitos deputados responderam que suas idas e vindas entre as comissões foram de fato negociadas ou impostas pelo líder do partido. Porém, outros indicaram que geralmente conseguiam ir para a comissão de sua preferência. É interessante notar que muitos justificaram preferir uma comissão a outra devido à sua especialização em determinado tema. Embora tal evidência não seja muito rigorosa, e possa ser interpretada de maneiras diferentes, para favorecer ou rejeitar cada teoria, é digno de nota que tanto os indivíduos como os partidos atribuem bastante valor a ser membro de uma comissão, o que sugere que as comissões devem realmente estar preenchendo algum papel relevante no processo legislativo.

Não há nenhuma forma definitiva de interpretar os gráficos para determinar qual teoria recebe mais apoio. Como nota Groseclose (1994b, p. 448), existe um contínuo de testes, dependendo do valor crítico que se escolhe, e geralmente os testes "não confirmam nem rejeitam sem controvérsia a conclusão geral de que as comissões tendem a ter preferências extremas". No nosso caso, chegar a uma conclusão é ainda mais difícil, dada a natureza dinâmica da composição das comissões. O que é claro, de acordo com os gráficos, é que diversas comissões têm suas medianas próximas ou acima do nível crítico mais alto em muitas das suas reuniões. A Comissão de Trabalho, de Administração e do Serviço Público (CTASP) é uma exceção e está sempre abaixo do nível crítico inferior. À primeira vista, este padrão aparenta favorecer a teoria distributiva. Porém, a existência de um nível de rotatividade tão alto, aliado ao fato de que muito desta rotatividade não é conseqüência da vontade própria dos parlamentares, é incompatível com a teoria distributiva. Se os deputados não tendem a permanecer na mesma comissão e podem ser substituídos contra a sua vontade, então as comissões não servem como compromissos críveis para realizar os ganhos de troca. É mais provável que a alta incidência de medianas próximas ou acima do valor crítico mais alto seja uma conseqüência da capacidade do Executivo de influenciar tanto os votos dos deputados como a composição das comissões. 


Os gráficos também mostram que as medianas de algumas comissões estão às vezes próximas à mediana do plenário, o que fornece alguma evidência de comissões representativas. Estas ocorrências não aparentam seguir nenhum padrão claro, tornando o apoio à teoria informacional fraco. ${ }^{19}$ É importante notar que a existência de alta rotatividade também desfavorece a teoria informacional, uma vez que os deputados têm menos oportunidade de se especializar se não podem permanecer na mesma comissão.

Diante das questões discutidas nos parágrafos precedentes, somos levados a afirmar que os resultados apresentados nos Gráficos 4, 5 e 6 são inconclusivos, uma vez que algumas comissões em certas ocasiões são representativas do plenário, em outras têm preferências extremas, e em outras ocasiões, ainda, não são nem representativas nem extremas. Ademais, não há nenhuma forma óbvia para determinar qual situação é mais freqüente.

Para testar a Hipótese 2, usamos dados de 225 propostas que foram aprovadas na Câmara no período de 1995 a $1998 .{ }^{20}$ Destas propostas, $56 \%$ receberam pedido de urgência. O teste consiste em rodar um probit sobre a escolha de urgência versus não urgência $\left(P^{U}\right.$ ou $\left.P^{N U}\right)$ usando uma série de variáveis de controle e, adicionalmente, uma variável que captura a distância entre a mediana da comissão e a mediana do plenário. A Hipótese 2 prevê que quanto maior for esta distância, maior será a probabilidade de urgência. A variável dependente, Urg, é igual a 1 se a urgência foi pedida, e igual a zero se não foi. A variável explicativa chave é $x_{c}$, que mede quão extrema era a preferência mediana da comissão para determinada proposta. $^{21}$ Esta variável foi construída calculando qual a porcentagem dos membros da Câmara com preferências entre a mediana do plenário e a mediana da comissão. Foi usado o valor absoluto desta porcentagem, pois o que nos interessa é a distância total e não a sua direção. Desta forma, comissões com preferências extremas estão mais próximas de 0,5 e as comissões mais representativas estão mais próximas de zero. A teoria informacional prevê que quanto menor for o valor de $x_{c}$, menor será a probabilidade de urgência. Além de $x_{c}$, adicionamos dois termos interativos que nos permitem separar o efeito de $x_{c}$ de acordo com quem iniciou a proposta, se o Executivo, o Legislativo ou o Judiciário. Assim, a variável Leg foi criada multiplicando $x_{c}$ a uma dummy igual a 1 se a proposta foi iniciada por um membro do Legislativo, e analogamente para a variável Jud. As variáveis de controle são dummies para as comissões e dummies que indicam o tema principal da proposta, se econômica (Eco), social (Soc), política (Pol) ou administrativa (esta é a dummy excluída). Finalmente, adicionamos também uma variável que mede o nível de heterogeneidade das preferências dentro das comissões, Het. ${ }^{22}$ Esta variável não fez parte do modelo apresentado neste trabalho, porém sua inclusão é sugerida por Gilligan e Krehbiel (1989), que propõem uma teoria compatível que argumenta que comissões mais heterogêneas são mais informativas do que comissões especializadas de um só lado do espectro de preferências. Portanto, a expectativa é encontrar uma maior probabilidade de não urgência $\left(P^{N U}\right)$ quando a comissão for mais heterogênea. A especificação da análise probit que rodamos é:

$U g_{i}=b_{0}+b_{1} x_{c i}+b_{2} \operatorname{Leg}_{i}+b_{3} \operatorname{Jud}_{i}+b_{4} \mathrm{Eco}_{i}+b_{5} \mathrm{Soc}_{i}$ $+b_{6} \mathrm{Pol}_{i}+b_{7} \mathrm{Het}_{i}+$ a Com $+e_{i}$

onde Com é um vetor com as dummies de comissão. Os resultados da análise probit estão apresentados na Tabela 1.

O principal resultado obtido nesta análise econométrica é o coeficiente positivo e estatisticamente significativo para $x_{i}$. Isto significa que, ceteris paribus, quanto mais distante for a preferência mediana da comissão da preferência mediana do plenário, maior será a probabilidade de se requisitar urgência para esta proposta. Isto confirma a Hipótese 2 , já que, de acordo com o modelo, quanto maior o valor de $x_{c}$, menos há para ser ganho em termos de informação ao se deixar a comissão examinar a proposta. Dada a existência de custos de espera, quanto menor for o ganho informacional, maior será o interesse do plenário e do Executivo em ter a proposta votada rapidamente. 
Tabela 1

Estimativas probit da escolha de urgência $\left(\mathrm{P}^{\mathrm{U}}\right)$ ou não urgência $\left(\mathrm{P}^{\mathrm{NU}}\right)$

\begin{tabular}{|c|c|}
\hline Variável & Coeficientes \\
\hline \multirow[t]{2}{*}{ Constante } & -2.037 \\
\hline & $(-0.870)$ \\
\hline \multirow{2}{*}{$x_{c}$} & $2.852 *$ \\
\hline & $(2.674)$ \\
\hline \multirow[t]{2}{*}{ Leg } & $-1.750 *$ \\
\hline & $(-2.891)$ \\
\hline \multirow[t]{2}{*}{ Jud } & -0.926 \\
\hline & $(-1.064)$ \\
\hline \multirow[t]{2}{*}{ Eco } & 0.324 \\
\hline & $(1.123)$ \\
\hline \multirow[t]{2}{*}{ Soc } & 0.040 \\
\hline & $(0.167)$ \\
\hline \multirow[t]{2}{*}{ Pol } & -0.165 \\
\hline & $(-0.293)$ \\
\hline \multirow[t]{2}{*}{ Het } & 0.263 \\
\hline & $(0.544)$ \\
\hline \multirow[t]{2}{*}{ CFT } & $0.484 *$ \\
\hline & $(2.180)$ \\
\hline \multirow[t]{2}{*}{ CAPR } & -0.832 \\
\hline & $(-1.209)$ \\
\hline \multirow[t]{2}{*}{ CCTCI } & 0.726 \\
\hline & $(1.257)$ \\
\hline \multirow[t]{2}{*}{ CDUI } & 0.918 \\
\hline & $(1.070)$ \\
\hline \multirow[t]{2}{*}{ CCJR } & 0.400 \\
\hline & $(0.896)$ \\
\hline \multirow[t]{2}{*}{ CTASP } & -0.494 \\
\hline & $(-1.101)$ \\
\hline \multirow[t]{2}{*}{ CDCMAM } & -0.2412 \\
\hline & $(-0.350)$ \\
\hline \multirow[t]{2}{*}{ CSSF } & 0.220 \\
\hline & $(0.461)$ \\
\hline \multirow[t]{2}{*}{ CEIC } & 0.127 \\
\hline & $(0.229)$ \\
\hline \multirow[t]{2}{*}{ CVT } & 0.943 \\
\hline & $(1.260)$ \\
\hline \multirow[t]{2}{*}{$\mathrm{CDN}$} & 0.765 \\
\hline & $(1.244)$ \\
\hline \multirow[t]{2}{*}{ CRE } & 0.237 \\
\hline & $(0.322)$ \\
\hline Log verosimilhança & -135.77 \\
\hline p-value para $\mathrm{H}_{0}$ : todos coef. $=0$ & 0.007 \\
\hline $\mathrm{N}$ & 225 \\
\hline$\%$ Corretos & $68,4 \%$ \\
\hline
\end{tabular}

t-stat. Assintótica entre parênteses.

* Significativo a $1 \%$.
Seria desejável que tivéssemos uma variável para medir os custos de espera associados a cada proposta. O coeficiente desta variável poderia, então, ser usado para testar a Hipótese 3. De acordo com o modelo, esperaríamos um coeficiente positivo para esta variável, já que propostas com altos custos de espera iriam levar o plenário e/ou o Executivo a pedir urgência. Fazer isto pode pôr a perder os potenciais ganhos informacionais, mas pode ser justificado se os custos de espera evitados compensarem esta perda. Embora não tenhamos dados para medir os custos de espera, podemos fazer algumas inferências a este respeito ao examinar a diferença entre as propostas iniciadas pelo Executivo e pelo Legislativo. A variável interativa Leg permite a inclinação do efeito de $x_{c}$ sobre a probabilidade de urgência ser diferente para as propostas iniciadas por cada um dos poderes. O coeficiente de Leg é negativo e significativo, porém menor do que $x_{i}$. Isto significa que, para propostas iniciadas pelo Legislativo, a distância entre a mediana da comissão e a mediana do plenário também tem um efeito positivo sobre a probabilidade de urgência, porém este efeito é menor do que nas propostas iniciadas pelo Executivo. Ou seja, para dado valor de $x_{c}$, uma proposta tem mais probabilidade de receber um pedido de urgência se tiver sido iniciada pelo Executivo.

Nós interpretamos este resultado como um suporte à Hipótese 3, relativa ao efeito dos custos de espera. $O$ argumento é que, no Congresso brasileiro, no período analisado, as propostas iniciadas pelo Executivo tiveram, na média, maiores custos de espera do que as propostas iniciadas pelo Legislativo. A razão para isto é a clara separação entre a natureza das legislações promovidas pelo Executivo e pelo Legislativo. Embora as dummies temáticas não tenham captado nenhum efeito sobre a probabilidade de urgência, as propostas iniciadas pelo Executivo tendem a ser predominantemente econômicas, ao passo que as propostas iniciadas pelo Legislativo tendem a ser predominantemente sociais. Dado o estado atual da economia brasileira, que passa por reformas fundamentais, a legislação econômica deverá ter, na média, maiores custos de espera do que a legislação social. Portanto, o maior efeito de $x_{c}$ sobre as 
propostas do Executivo é consistente com a noção de que estas têm maiores custos de espera.

Finalmente, gostaríamos de poder testar também se as propostas que envolvem maior nível de incerteza tiveram uma menor probabilidade de receber pedidos de urgência, com as outras variáveis mantidas constantes (Hipótese 4). Quanto maior é o nível de incerteza, maior será o estrago que esta legislação poderá causar a todos os atores, e portanto, mais valiosa será a informação que a comissão poderá revelar caso lhe seja permitido examinar a proposta. Infelizmente, medir a incerteza envolvida em determinada proposta é uma tarefa muito complexa e não temos como testar esta hipótese com estes dados.

\section{Conclusões}

Este trabalho analisou o funcionamento do sistema de comissões no Congresso brasileiro usando os modelos e instrumentos da literatura de escolha racional desenvolvida para o Congresso dos EUA. O fato mais marcante do Congresso brasileiro são os extensos poderes legislativos do Executivo. Entre outros poderes, o Executivo brasileiro pode iniciar legislação, retirar propostas das comissões via pedido de urgência, vetar em parte ou no todo legislação aprovada no Congresso, influenciar na composição das comissões, influenciar na escolha dos presidentes e relatores das comissões e criar comissões especiais. Uma conseqüência direta dessa extrema preponderância do Executivo é a fragilidade de nossas comissões parlamentares, em contraste marcante com as comissões do Congresso dos EUA. Este trabalho buscou examinar se, dada esta situação, as comissões brasileiras são essencialmente irrelevantes ou se elas desempenham algum papel no processo legislativo.

Uma das mais importantes instituições do Congresso brasileiro é o pedido de urgência, que é amplamente usado e representa um importante limite sobre o poder das comissões. Mostramos que, apesar da existência deste instrumento, o Executivo deu-se ao trabalho de fazer com que as comissões tivessem, em geral, membros medianos leais aos seus interesses, o que sugere que as comissões podem desempenhar algum papel rele- vante para o Executivo. Nossa primeira tentativa de encontrar tal propósito foi seguir a sugestão da teoria distributiva (Shepsle e Weingast, 1987) de que o veto ex-post seria a base do poder das comissões. Adaptamos esta idéia para argumentar que o Executivo, no Brasil, pode se beneficiar de contar com um conjunto de comissões leais que, investidas com a ameaça de um veto presidencial, poderiam defender os seus interesses no Congresso. Este arranjo institucional serviria para facilitar propostas do interesse do Executivo, barrar propostas contrárias e evitar confrontos no plenário. No entanto, este papel nos pareceu insuficiente para explicar a existência de um sistema de comissões tão complexo. Voltamo-nos, então, ao instrumental da teoria informacional para observar se as comissões desempenhariam, alternativamente, o papel de gerar informação e reduzir incertezas.

Com este objetivo, foi montado um modelo informacional para o processo legislativo brasileiro baseado em Gilligan e Krehbiel (1987). Este modelo teve como referência a premissa de que as comissões são capazes de se especializar e adquirir informação a respeito dos projetos e também de decidir estrategicamente quanto desta informação será revelada ao plenário. $O$ equilíbrio alcançado neste jogo indica que, exceto pelo custo de espera, todos os atores envolvidos preferem que não haja um pedido de urgência, pois assim a comissão pode obter e revelar informações, ajudando a reduzir a incerteza que prejudica a todos. O ganho informacional para o plenário e para o Executivo é maior que a perda distributiva. No entanto, devido aos custos de espera, em muitas circunstâncias o plenário e/ou o Executivo podem preferir pedir urgência. A principal hipótese testável gerada por este modelo é a de que quanto mais extremas forem as preferências da comissão, ceteris paribus, maior será a probabilidade de ocorrer um pedido de urgência. Isto acontece porque quanto maior for a distância entre as preferências medianas da comissão e as do plenário, menos informação será revelada pela comissão em equilíbrio, de modo que será maior a probabilidade do custo de espera contrabalançar o ganho informacional.

Esta hipótese foi testada usando um teste probit sobre a decisão de pedir ou não urgência. 
Foi encontrada forte evidência de que a probabilidade de urgência aumenta à medida que aumenta a distância entre as preferências medianas da comissão e do plenário. Isto é, sendo controladas por outras variáveis importantes, aquelas comissões com preferências mais extremas tendem a receber pedidos de urgência mais freqüentemente. É exatamente isto que seria previsto pela teoria informacional. As comissões mais representativas do plenário é que teriam maior chance de reduzir a incerteza, pois estariam em equilíbrio com o plenário, de modo que nelas seria menor a probabilidade de pedidos de urgência.

Certamente o Congresso brasileiro e seu sistema de comissões são muito mais complexos do que o retratado neste artigo. Talvez a nossa mais importante contribuição tenha sido mostrar que, apesar das importantes diferenças existentes entre as instituições políticas do Brasil e dos EUA, os modelos de escolha racional da Teoria Política Positiva podem ser usados para analisar e entender os atores políticos brasileiros e suas relações. Existe uma enorme agenda de pesquisa, que só agora começa a ser explorada, a ser desenvolvida aplicando-se esta literatura ao rico conjunto de instituições e situações brasileiras.

\section{Apêndice}

\section{O modelo}

Neste apêndice formalizamos o argumento apresentado sobre o papel informacional das comissões. Este modelo é baseado em Gilligan e Krehbiel (1987) e adaptado às instituições brasileiras. A chave do modelo é a relação de incerteza existente entre as políticas, $p$, e seus resultados, $x$. Esta relação é expressa como $x=p+\omega$, onde $\omega$ é uma variável aleatória uniforme distribuída no intervalo $[0,1] .^{23}$ Os três atores considerados no modelo são o eleitor mediano da Câmara, doravante chamado de plenário, o eleitor mediano da comissão e o Executivo. Cada ator tem um ponto ideal, $x_{f}, x_{c}$ e $x_{p}$, respectivamente. Para simplificar, e sem perda de generalidade, $x_{f}$ é normalizado para zero e $x_{c}$ e $x_{p}$ são presumidos positivos. Todos os atores são avessos ao risco e têm funções de utilidade quadráticas que decrescem à medida que o resultado final se afasta de seus pontos ideais:

$\mu_{\mathrm{f}}=-\left(\mathrm{x}-\mathrm{x}_{\mathrm{f}}\right)^{2}-\mathrm{k}^{\mathrm{f}}=-\mathrm{x}^{2}-\mathrm{ak}^{\mathrm{f}}$

$\mu_{\mathrm{c}}=-\left(\mathrm{x}-\mathrm{x}_{\mathrm{c}}\right)^{2}-\mathrm{ak}^{\mathrm{c}}$

$\mu_{\mathrm{p}}=-\left(\mathrm{x}-\mathrm{x}_{\mathrm{f}}\right)^{2}-\mathrm{ak}^{\mathrm{p}}$

onde $k^{f}, k^{c}$ e $k^{p}$ são os custos de espera incorridos por cada ator por ter a proposta analisada em vez de votada imediatamente. A variável a é igual a zero ou um conforme se permita ou não o exame da proposta pela comissão.

A estrutura do jogo é mostrada na Figura 2, que representa uma versão estilizada do fluxo de legislação no Congresso brasileiro. Uma proposta é apresentada na comissão, mas antes que esta a examine, ou mesmo durante o processo de análise, o Executivo e/ou o plenário podem requerer urgência. Supomos que não há um custo para requerer urgência. ${ }^{24}$ Mediante o pedido de urgência, a proposta será inserida na próxima sessão legislativa quer a comissão tenha concluído ou não seu parecer. Se tanto o Executivo como o plenário pedirem urgência, $a=1$; caso contrário $a=0$. Se não houver pedido de urgência a comissão dedicará tempo e esforço para analisar o assunto, debater, promover audiências etc. No modelo, esta fase está representada pela comissão aprendendo o verdadeiro valor de $\omega$. A comissão então elabora uma proposta, b, que será enviada ao plenário. $^{25}$ Este atualiza suas crenças (beliefs) após observar a mensagem da comissão e, então, escolhe a política $p$ de forma a maximizar sua utilidade esperada levando em conta qual a melhor resposta às estratégias dos outros atores.

Para definir o resultado deste jogo, este foi dividido em um jogo legislativo e um jogo de procedimento. $\mathrm{O}$ equilíbrio legislativo define $\mathrm{o}$ resultado quando a urgência não é requisitada e a comissão examina a proposta. Baseado neste resultado, o equilíbrio do jogo de procedimento determina se o plenário e/ou o Executivo irão pedir urgência.

Para definir o equilíbrio legislativo temos de especificar a estratégia para o plenário e para a comissão supondo que a urgência não foi requisitada. O conceito de equilíbrio usado é o de 
equilíbrio seqüencial (Kreps e Wilson, 1982). Uma estratégia para o plenário é uma política $p$ que, dado suas crenças sobre $\omega$ e a mensagem $b$, maximize sua utilidade esperada. Uma estratégia para a comissão é uma proposta $b$ que seja uma resposta ótima, dado que o plenário está seguindo sua estratégia ótima. Finalmente, as crenças do plenário devem se confirmar no equilíbrio. Isto é:

Definição 1. Um equilíbrio legislativo seqüencial é um conjunto de estratégias $b^{*}(),$.$p , e$ crenças $\mu^{*}($.$) tais que:$

1. Para todo $\omega \in \Omega b^{*}(\omega) \in \operatorname{argmax}_{b} E \mu_{c}\left(p^{*}(b), \omega\right)$;

2. Para todo $b, p^{*}(b) \in \operatorname{argmax}_{p} \int_{\omega} E \mu_{\mathrm{f}}\left(\mathrm{p}\left(\mathrm{b}^{*}\right), \omega\right) \mu^{*}$ $(\omega / b) d \omega$

3. $\mu^{*}(b) \subseteq[0,1]$ para todo $b$ e $\mu^{*}(b)=$ $\left\{\omega / b=b^{*}(\omega)\right\}$ sempre que $\mu^{*}(b)$ for não vario.

Esta definição afirma que em equilíbrio (1) a comissão maximiza sua utilidade esperada dado que o plenário está seguindo sua melhor estratégia; (2) o plenário escolhe sua estratégia ótima dado suas crenças sobre $\omega$; e (3) o plenário tem crenças consistentes com a estratégia ótima da comissão e elas se realizam no equilíbrio.

O próximo passo é determinar o equilíbrio do jogo de procedimento, ou seja, se urgência será ou não requisitada. Neste jogo, o plenário e o Executivo escolhem o procedimento (urgência ou não urgência) de forma a maximizar sua utilidade esperada dado o equilíbrio legislativo acima.

Definição 2. O equilíbrio para o jogo de procedimento é um procedimento $P^{*}$ tal que:

$\mathrm{ou}$

$E \mu_{\mathrm{f}}\left(\mathrm{P}^{*} / \mathrm{b}^{*}(\omega), \mathrm{p}^{*}(\mathrm{~b}), \mu(\mathrm{b})\right) \geq \mathrm{E} \mu_{\mathrm{f}}\left(\mathrm{P}^{\prime} / \mathrm{b}^{*}(\omega), \mathrm{p}^{*}(\mathrm{~b}), \mu(\mathrm{b})\right)$, para $\mathrm{P}^{*} \neq \mathrm{P}^{\prime}$

ou

$\mathrm{E} \mu_{\mathrm{p}}\left(\mathrm{P}^{*} / \mathrm{b}^{*}(\omega), \mathrm{p}^{*}(\mathrm{~b}), \mu(\mathrm{b})\right) \geq \mathrm{E} \mu_{\mathrm{p}}\left(\mathrm{P}^{\prime} / \mathrm{b}^{*}(\omega), \mathrm{p}^{*}(\mathrm{~b}), \mu(\mathrm{b})\right)$, para $\mathrm{P}^{*} \neq \mathrm{P}^{\prime}$

Esta definição afirma que tanto o Executivo como o plenário olham para frente e comparam seus pay-offs no caso de urgência ser requisitada com seus pay-offs no caso de urgência não ser requisistada e da comissão examinar a proposta. Se qualquer um dos dois preferir o resultado com urgência, eles a requisitarão e conseqüentemente $a=1$. Ou seja, o equilíbrio do jogo de procedimento será $P^{*}=P^{U}$. Caso nenhum dos dois prefira urgência, $a=0$ e $P^{*}=P^{N U}$.

Equilíbrio com e sem urgência

Para ilustrar o funcionamento do modelo, mostraremos um exemplo do equilíbrio alcançado quando $x_{c}=1 / 18$, sob cada um dos procedimentos, $P^{U}$ e $P^{N U}$. A Figura 3 mostra o equilíbrio que resulta quando urgência é requisitada $\left(P^{*}=P^{U}\right)$, de modo que a proposta vai direto para o plenário para ser votada sem ser examinada pela comissão e, como conseqüência, esta não tem a oportunidade de aprender $\omega$. Neste caso, mesmo que a comissão mande uma mensagem $b$,

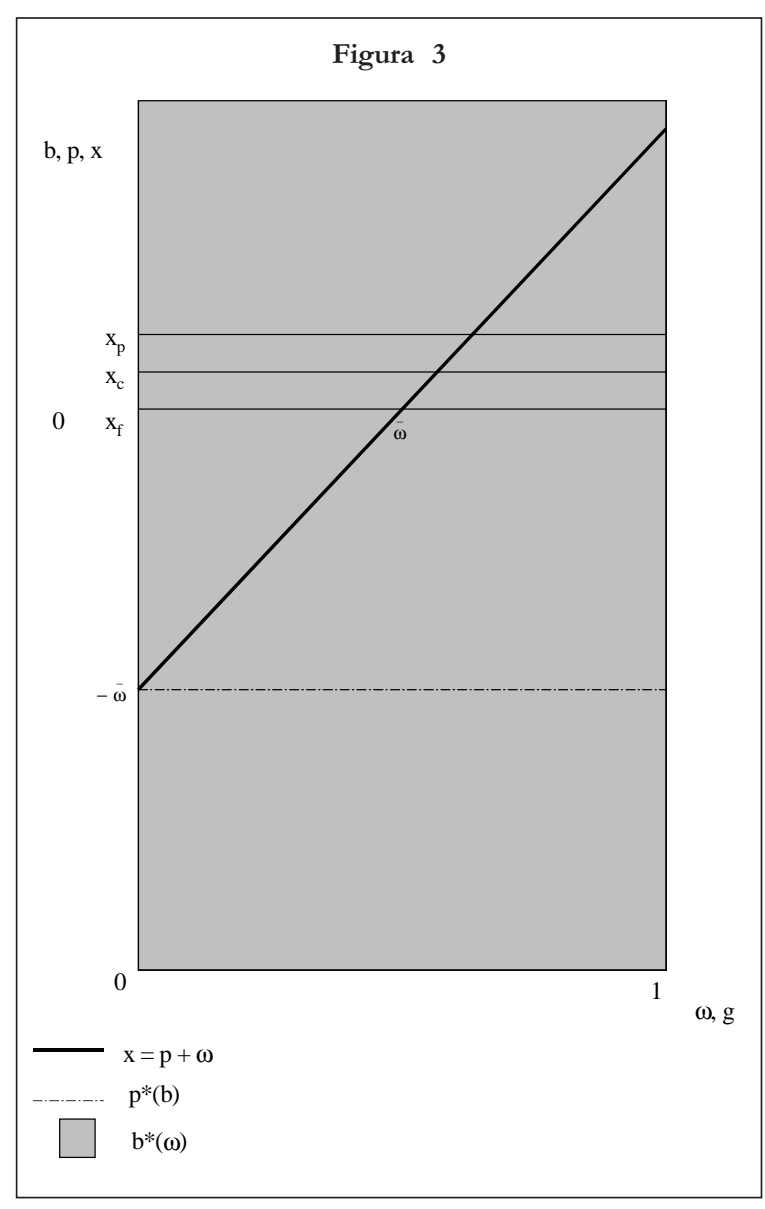


o plenário percebe que esta mensagem não traz informação nova sobre $\omega$. A resposta racional para o plenário, neste caso, é tomar $\omega$ pelo seu valor médio $\omega^{-} \mathrm{Na}$ figura, o eixo horizontal mede o valor realizado de $\omega$ e as crenças do plenário $\mu$. O eixo vertical mede a proposta da comissão, $b$, a política escolhida pelo plenário, $p$, e o resultado final que é igual a $p+\omega$. Os pontos ideais de cada um dos atores estão mostrados no eixo vertical, $\operatorname{com} x_{f}=0, x_{c}=1 / 18$ e $x_{p}=2 / 18$. A linha pontilhada mostra que neste equilíbrio $o$ plenário escolhe sempre $-\bar{\omega}$, independente da mensagem enviada pela comissão. A linha diagonal em negrito mostra o resultado final $x$ para cada realização possível de $\omega$, dado este comportamento pelo plenário. Note que o resultado esperado para o plenário é $x=0$, que é seu ponto preferido. No entanto, dependendo do valor realizado por $\omega$, o resultado final pode vir a ser consideravelmente distante deste ponto. Expressões para as utilidades esperadas são obtidas somando as utilidades ponderadas sob cada realização possível de $\omega$.

Quando $P^{*}=P^{U}$ nós temos que $\mathrm{E}_{f_{2}}^{U}=-\sigma_{\omega}^{2}$, $\mathrm{E}_{c}^{U}=-\sigma_{\omega}^{2}-\mathrm{x}_{C}^{2}$ e $\mathrm{E}_{p}^{U}=-\sigma_{\omega}^{2}$. O termo $\sigma_{\omega}^{2}$ representa a perda informacional sofrida por cada ator. Somado a isto, a comissão sofre uma perda distributiva de $-x_{C}^{2}$ e o Executivo, uma perda distributiva de $-x_{p}^{2}$.

Se nem o Executivo nem o plenário pedirem urgência para uma dada proposta $\left(P^{*}=P^{N U}\right)$, então a comissão terá a oportunidade de examinar a proposta e aprender o verdadeiro valor de $\omega$. A comissão mandará então uma mensagem estrategicamente elaborada para o plenário, que por sua vez a interpretara como tal. A Figura 4 mostra o equilíbrio que resulta quando $P^{*}=P^{N U}$. Este equilíbrio é típico de jogos de sinalização (signaling games), com a comissão sinalizando uma região onde $\omega$ caiu em vez de um valor específico. Suponha que $\omega$ tenha caído na região $\left[0, a_{1}\right]$. A comissão, neste equilíbrio, irá mandar qualquer mensagem entre 0 e $a_{1}$, levando o plenário a atualizar as suas crenças para considerar somente estes valores de $\omega$ como possíveis. O resultado para esta região é dado pela linha diagonal em negrito, que sobe a um ângulo de 45 graus. A mesma lógica funciona para os outros intervalos. $\mathrm{Na}$ fronteira entre os intervalos, a comis-

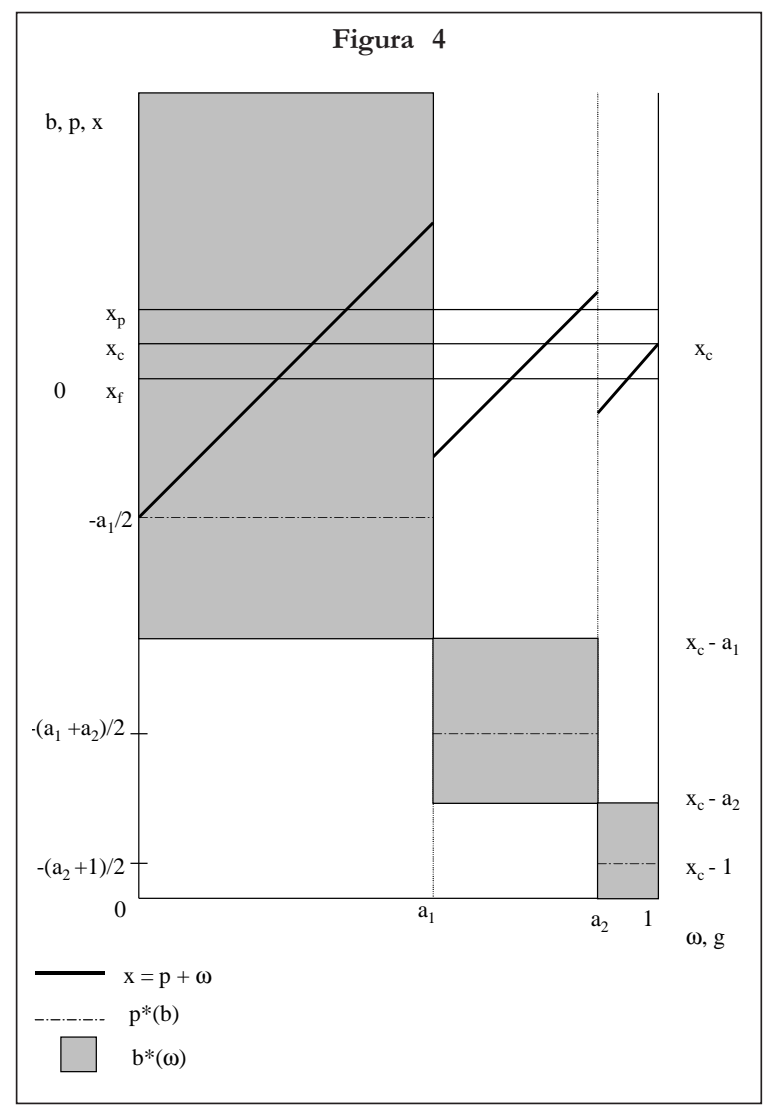

são deve ser indiferente entre os resultados em cada intervalo adjacente. ${ }^{26}$ Pode-se mostrar que, neste equilíbrio, a comissão tem de fato interesse em sinalizar o verdadeiro intervalo que contém $\omega$. Note que, como no caso em que $P^{*}=P^{U}$, o resultado esperado do plenário é igual a seu ponto preferido. Porém, pode-se notar pelos gráficos que sua utilidade esperada é maior do que no caso anterior, já que os valores absolutos dos resultados são menos distantes de $x_{f}$. O fato de que os agentes são avessos ao risco (funções de utilidade quadráticas) significa que recebem benefícios da redução de incerteza proveniente do aumento de informação que é transmitida. Os valores precisos das utilidades dos agentes são:

$\mathrm{E}_{\mathrm{f}}^{\mathrm{NU}}=-\frac{\sigma_{\omega}^{2}}{\mathrm{~N}^{2}}-\frac{\mathrm{X}_{\mathrm{c}}^{2}\left(\mathrm{~N}^{2}-1\right)}{3}-\mathrm{k}^{\mathrm{f}}, \mathrm{E}_{\mathrm{c}}^{\mathrm{NU}}=\frac{\sigma_{\omega}^{2}}{\mathrm{~N}^{2}}-\frac{\mathrm{X}_{\mathrm{c}}^{2}\left(\mathrm{~N}^{2}-1\right)}{3}--\mathrm{X}_{\mathrm{c}}^{2}-\mathrm{k}^{\mathrm{c}}$, e $\mathrm{E}_{\mathrm{p}}^{\mathrm{NU}}=-\frac{\sigma_{\omega}^{2}}{\mathrm{~N}^{2}}-\frac{\mathrm{X}_{\mathrm{c}}^{2}\left(\mathrm{~N}^{2}-1\right)}{3}-\mathrm{X}_{\mathrm{p}}^{2}-\mathrm{k}^{\mathrm{p}}$, onde $N$ é o número de intervalos para dado equilíbrio. 
O termo $-\frac{\sigma_{\omega}^{2}}{N^{2}}-\frac{X_{c}^{2}\left(N^{2}-1\right)}{3}$ representa a perda informacional que cada ator sofre. Somado a isto, a comissão e o Executivo ainda sofrem uma perda distributiva de $-\mathrm{X}_{\mathrm{c}}^{2}$ e $-\mathrm{X}_{\mathrm{p}}^{2}$, respectivamente. Finalmente, cada ator ainda tem uma perda devido ao custo de espera, ou seja, devido ao fato de $P^{N U}$ levar mais tempo para gerar resultados do que $P^{U}$. $O$ equilíbrio mostrado na Figura 4 não é único. Neste tipo de jogo geralmente existem diversos equilíbrios com diferentes números de partições. O equilíbrio mostrado aqui é aquele com o maior número de partições $(N=3)$ dado $x_{c}=1 / 18$. É portanto o equilíbrio que gera a maior redução de incerteza e pode-se argumentar que há boas razões para escolhê-lo (Gilligan e Krehbiel, 1987, p. 308; Crawford e Sobel, 1982, pp. 1.442-1.443). Note que o número de partições máximo pode ser aumentado à medida que $x_{c}$ diminui. No limite, $x_{c}$ é igual a $x_{f}$ e $N$ é igual a infinito, ou seja, a linha pesada que representa o resultado alcançado seria sobre $x_{f}$ No outro extremo, uma vez que as preferências da comissão forem suficientemente distantes daquelas do plenário (mais precisamente, para $x_{c} \geq 3 \sigma_{\omega}^{2}$ ), o equilíbrio fica idêntico àquele $\mathrm{da}$ Figura 3 , onde $N=1$ e não há transmissão de informação pela comissão.

Agora podemos analisar a escolha de procedimento entre $P^{U}$ e $P^{N U}$ para derivar hipóteses testáveis. Os Gráficos 1, 2 e 3 mostram as utilidades esperadas para cada ator, sob cada procedimento, como uma função de $\chi_{c}$, a distância entre as preferências da comissão e do plenário. ${ }^{27}$ Note que para dados valores de custos de espera as utilidades esperadas de cada ator não aumentam à medida que $x_{c}$ aumenta. Todos os atores atingem sua mais alta utilidade possível quando as preferências do plenário são idênticas às da comissão $\left(x_{c}=0\right)$, pois neste caso a comissão revela o valor exato de $\omega$. Presumindo um custo de espera igual a zero, a utilidade do plenário sem urgência é mais alta do que com urgência para valores baixos de $x_{i}$. Isto permanece sendo o caso até o ponto onde $x_{c}=3 \sigma_{\omega}^{2}=0.25$, após o qual os resultados para o plenário são iguais para ambos os procedimentos. À medida que aumentam os custos de espera do plenário, o procedimento sem urgência torna-se menos atraente com relação ao procedimento com urgência. Para custos de espera tais que $\mathrm{k}^{\mathrm{f}}>3 \sigma_{\omega}^{2}$ o plenário irá preferir urgência, independente de $x_{c}$, e portanto urgência será requisitada. A comissão e o Executivo também irão preferir não urgência a urgência

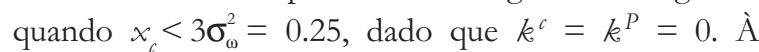
medida que seus custos de espera aumentam, os valores de $x_{\text {, }}$ para os quais urgência é preferível a não urgência ficam maiores. Para valores suficientemente altos de $k^{c}$ e $k^{p}$ eles sempre preferirão urgência.

\section{NOTAS}

1 Sobre o modelo principal-agent neste contexto ver Weingast (1984).

2 Este trabalho se refere ao funcionamento do Congresso brasileiro desde a vigência da Constituição de 1988. Os dados empíricos são da legislatura 1995-1998.

3 Alguns trabalhos que tratam especificamente deste tema são Pereira (2000a), Figueiredo e Limongi (1996 e 1999) e Nicolau (1999).

4 A taxa de aprovação das propostas do Executivo é muito alta e rejeições são raras — somente 11 (2,4\% do total) na legislatura 1995-1998. O contrário ocorre com as propostas do Legislativo. Desde sua instituição pela Constituição de 1988, das 4.422 Medidas Provisórias editadas, apenas 21 foram rejeitadas pelo Congresso Nacional. Dentre elas, 9 no governo Sarney, 11 no governo Collor, nenhuma durante o governo Itamar Franco e apenas uma no governo Fernando Henrique Cardoso até o dia 30 de novembro de 1999 (O Globo, 2/ 12/1999)

5 Como foi mostrado por Figueiredo e Limongi (1995), este padrão de controle do Executivo sobre a agenda do Legislativo não é privilégio do atual governo. Presidentes dominam o processo legislativo desde 1989. De 1.259 leis aprovadas entre 1989 e 1994, 997 foram iniciadas pelo Executivo, contra 176 iniciadas pelos legisladores e 86 pelo Judiciário.

6 Mais precisamente, o tempo médio de aprovação de propostas do Executivo é de 26 dias para as Medidas Provisórias; 58 dias para leis orçamentárias; 374 dias para leis administrativas e 375 dias para leis ordinárias.

7 Comissões especiais também são criadas quando se trata de uma emenda constitucional. Como a agenda do Congresso, na década de 1990, tem sido objeto de um grande número de emendas constitucionais, não surpreende que o Executivo venha demonstrando um interesse especial em ter presidentes e relatores leais nas comissões especiais.

8 Pelo regimento da Câmara, os legisladores têm cinco sessões para emendar ou derrubar uma proposta aprovada por poder conclusivo. Para que o plenário possa 
fazer isto bastam assinaturas de um décimo dos seus membros.

9 Pereira (2000a) mostra que um dos principais determinantes do voto dos parlamentares em favor do Executivo no plenário da Câmara dos Deputados de 1995 a 1998 foi a execução das emendas individuais dos deputados ao orçamento dos respectivos anos pelo Ministério da Fazenda.

10 Legislação que cai na jurisdição da Comissão de Trabalho, de Administração e do Serviço Público (CTASP), por exemplo, que foi a comissão com composição mais contrária ao Executivo no período 1995-1998, parece seguir este padrão geral. De todos as propostas que foram enviadas a esta comissão, $56 \%$ receberam pedido de urgência. Além disso, $26 \%$ de todos os vetos foram sobre legislação que passou por esta comissão.

11 Para uma boa revisão crítica de diversos testes veja Groseclose (1994a e 1994b).

12 O único índice que encontramos disponível é aquele que mede as preferências dos deputados com relação a direitos dos trabalhadores, criado pelo Departamento Intersindical de Assessoria Parlamentar (DIAP).

13 Seria preferível tentar identificar os principais interesses representados em cada comissão e usar somente os votos relacionados com assuntos relevantes a estes temas. Porém, após entrevistar pessoas que trabalham nas comissões, descobrimos que é muito difícil identificar os temas relevantes e também as votações relevantes para cada comissão. Optamos, portanto, por usar um índice geral, embora admitamos que esta não é a situação ideal. $O$ índice foi criado usando a seguinte fórmula: índice $=\ln \left(r_{i}+0,5\right) /\left(n_{i}-r_{i}+0,5\right)$, onde $r_{i}$ é o número de votos favoráveis dado pelo legislador $i$ e $n_{i}$ é o número de votações da qual o legislador $i$ participou. Adicionalmente o índice foi corrigido para heterocedasticidade.

14 Para testar isto, comparamos nosso índice com o índice do DIAP e observamos que eles apresentam uma alta correlação.

15 Por restrições de espaço, apresentamos apenas os gráficos para três comissões. Entretanto, os gráficos das outras comissões, bem como os dados do restante do trabalho, encontram-se disponíveis em bmueller@unb.br ou pereirace@uol.com.br.

16 Note que os valores críticos variam com o tamanho das comissões.

$17 \mathrm{O}$ que sugere a necessidade de testar se esta variabilidade é aleatória ou se pode ser explicada pelas características das propostas consideradas na comissão a cada momento. Isto não será feito neste trabalho, mas entendemos que esta investigação pode ser objeto de pesquisa futura.

18 Como o número de deputados que respondeu aos questionários foi relativamente baixo, evitamos colocar muita ênfase sobre estes resultados.

19 Note, porém, que a teoria informacional, tal como apresentada em Krehbiel (1991, cap.3), admite comissões com preferências extremas ao levar em conta os custos de especialização. Nós não temos nenhuma indicação de até que ponto isto pode estar acontecendo no nosso caso.

20 Neste período, 805 propostas foram aprovadas pela Câmara. Deste total eliminamos 128 Medidas Provisórias (para as quais urgência não é relevante), as leis que passaram por comissões mistas do Senado e da Câmara (principalmente questões orçamentárias) e as propostas da jurisdição das quatro comissões para as quais não tínhamos dados.

21 Dado que a mediana da comissão pode ter variado ao longo do tempo, usamos a mediana média para o ano em que a proposta passou pela comissão.

22 Esta variável foi construída levando em conta o desvio padrão médio da preferência dos membros da comissão no ano em que a proposta passou pela comissão. O desvio padrão das preferências do plenário como um todo foi de 4,38, ao passo que o desvio padrão nas comissões variou de 3,54 a 5,72 .

23 A política $p$ provém de um espaço unidimensional $P \in R^{1}$. A distribuição de $\Omega$, onde $\omega \in \Omega$, é de conhecimento de todos os atores. A média e a variância de $\Omega$ são $\bar{\omega}=1 / 2$ e $\sigma_{\omega}^{2}=1 / 12$.

24 Esta premissa é feita porque, como foi explicado anteriormente, as regras da Câmara fazem com que seja fácil requerer urgência. Na legislatura 1995-1998, a urgência foi pedida para $210(31 \%)$ das 677 propostas aprovadas.

25Trata-se de um jogo de cheap-talk de informação incompleta, como em Crawford e Sobel (1982). A proposta enviada pela comissão é sua mensagem para o plenário. A mensagem tem espaço $b \in[0,1]$.

26 Este é simplesmente o equilíbrio original de Crawford e Sobel (1982).

27 As utilidades esperadas para os casos sem urgência foram calculadas usando o número mais alto de partições para cada valor de $x_{c}$ e custos de espera de 0,02 . É fácil perceber que estes custos de espera simplesmente movem as curva para cima e para baixo.

\section{BIBLIOGRAFIA}

BERNARDES, Franco C. (1996), Democracia concentrada: a estrutura do poder decisório na Câmara dos Deputados. Tese de mestrado em Ciência Política, Rio de Janeiro, Iuperj.

COX, Gary W. e MCCUBBINS, Mathew D. (1993), Legislative leviathan: party government in the House. Berkeley, University of California Press.

(1994). "Bonding, structure, and the stability of political parties: party government in the House". Legislative Studies Quarterly, 2: 215-32.

CRAWFORD, V.P. e SOBEL, J. (1982), "Strategic information transmission". Econometrica, 50 (6): 1.431-51. 
EPSTEIN, David. (1997), "An informational rationale for committee gatekeeping power". Public Choice, 91: 3-4.

FIGUEIREDO, Argelina C. e LIMONGI, Fernando. (1995), "Mudança constitucional, desempenho legislativo e consolidação institucional". Revista Brasileira de Ciências Sociais, 29.

(1996), "Congresso Nacional: organização, processo legislativo e produção legal”. Cadernos de Pesquisa, São Paulo, Cebrap, 5.

(1997), Presidential power and party behavior in the legislature. Trabalho apresentado em reunião da Latin American Studies Association (LASA), Guadalajara, México.

$$
\text { (1999), Executivo e Legislativo na nova }
$$
ordem constitucional. São Paulo, Ed. da FGV.

GIBBONS, R. (1992), Game theory for applied economists. Princeton, Princeton University Press.

GILLIGAN, Thomas e KREHBIEL, Keith. (1987), “Collective decision-making and standing committees: an informational rationale for restrictive amendment procedures". Journal of Law, Economics, and Organization, 3: 287-335.

GROSECLOSE, T. (1994a), "The committee outlier debate: a review and a reexamination of some of the evidence". Public Choice, 80: 3-4.

(1994b), "Testing committee composition hypotheses for the U.S. Congress". The Journal of Politics, 56 (2), May: 440-58.

KREHBIEL, Keith. (1991), Information and legislative organization. Ann Arbor, University of Michigan Press.

KREPS, D.M. e WILSON, R. (1982), "Sequential equilibria”. Econometrica, 50 (4): 863-94.

LEONI, Eduardo, (2000), Organização legislativa em perspectiva comparada. Projeto de dissertação de mestrado apresentado ao Departamento de Relações Internacionais da Universidade de Brasília.

MAINWARING, Scott. (1999), Rethinking party systems in the third wave of democratization: the case of Brazil. Stanford, Stanford University Press.

MAINWARING, Scott e SHUGART, Matthew S. (1997), Presidentialism and democracy in Latin America. Cambridge, Cambridge University Press.

McCUBBINS, Mathew e SULLIVAN, Terry. (1987), Congress: structure and policy. Cambridge, Cambridge University Press.
NICOLAU, Jairo M. (1996), Multipartidarismo e democracia. Rio de Janeiro, Ed. da Fundação Getúlio Vargas.

(1999), Sistemas eleitorais. Rio de Janeiro, Ed. da Fundação Getúlio Vargas.

PEREIRA, Carlos. (2000a), What are the conditions for presidential success in legislative arena: the Brazilian electoral connection. Tese de doutorado, Nova York, The New School for Social Research.

(2000b), "Why the Brazilian legislators have decided to clean up their sidewalkers? The influence of the Brazilian political institutions on the process of state reform", in Stuart Nagel (ed.), Handbook of global political policy, Nova York, Marcel Dekker.

SANTOS, Fabiano G. (1999), Party leaders and committee assignments in Brazil. Trabalho apresentado na 1999 Annual Meeting of the American Political Science Association, Atlanta, September $2-5$.

SHEPSLE, Kenneth A. e WEINGAST, Barry. (1987), "Institutional foundations of committee power". American Political Science Review, 81: 85-104.

SHEPSLE, Kenneth A. e BONCHEK, Mark S. (1997), Analyzing politics: rationality, behavior, and institutions. Nova York, W.W. Norton and Company.

SHUGART, Matthew S. e CAREY, John M. (1992), Presidents and assemblies - constitutional design and electoral dynamics. Cambridge, Cambridge University Press.

WEINGAST, B.R. (1984), "The congressional-bureaucratic system: a principal-agent perspective (with applications to the SEC)". Public Choice, 44 (1): 147-91.

WEINGAST, B.R. e MARSHALL, W.J. (1988), "The industrial organization of Congress; or, why legislatures, like firms, are not organized as markets". Journal of Political Economy, 96 (1): 133-63. 